\title{
Strawberry gums: a clinicopathological manifestation diagnostic of Wegener's granulomatosis?
}

\author{
S S Napier, J A Allen, C R Irwin, D R McCluskey
}

\begin{abstract}
Aims-To highlight an uncommon but characteristic gingival lesion associated with Wegener's granulomatosis, emphasising the presence of pseudoepitheliomatous hyperplasia, microabscesses, and multinucleate giant cells; and the paucity of the currently accepted histopathological criteria of Wegener's granulomatosis-namely necrosis, vasculitis, and granulomata.

Methods-The histopathological features of a gingival biopsy specimen from a case of Wegener's granulomatosis limited to the upper aerodigestive tract in a 36 year old woman were compared with those of 14 similar reported cases.

Results-Pseudoepitheliomatous hyperplasia, microabscesses, and multinucleate giant cells were recorded as present in almost all cases of gingival Wegener's granulomatosis. Necrosis, vasculitis, and granuloma formation were present in only a few cases.

Conclusions-The combination of pseudoepitheliomatous hyperplasia, microabscesses, and multinucleate giant cells in a gingival biopsy specimen from erythematous, swollen gums, clinically resembling over-ripe strawberries, in a patient with a severe systemic upset, is so typical of Wegener's granulomatosis as to be virtually diagnostic. Recognition of this characteristic lesion may aid early diagnosis and treatment in cases where other diagnostic variables are absent.
\end{abstract}

$(\mathcal{F}$ Clin Pathol 1993;46:709-712)

Prompt definitive diagnosis is important in Wegener's granulomatosis: the prognosis has been greatly improved by early instigation of appropriate treatment. ${ }^{1}$ Serological tests can be of help, especially the identification of high cytoplasmic staining anti-neutrophil cytoplasmic antibody (cANCA) titres. But these may be negative in 15-33\% of cases, particularly those without renal disease. ${ }^{2}$ Current histopathological criteria for the diagnosis of Wegener's granulomatosis are stringent, requiring identification of vasculitis, ill defined granulomata, multinucleate giant cells, and necrosis, ${ }^{34}$ although some authors maintain that the patterns of the necrosis are sufficiently characteristic to allow a diagnosis to be made from this feature alone. ${ }^{56}$ The lesions may be sparsely distributed through the tissues and are frequently not identified in small biopsy specimens, even in those from sites of active disease in the nose, lung, or kidney.

It is worth emphasising that Wegener's granulomatosis cannot be diagnosed by the clinician or pathologist in isolation. It requires good interaction between clinical and laboratory disciplines, and careful correlation of the results of all available investigations with the clinical presentation. ${ }^{7}$

We draw attention to histopathological features, which have been consistently described, though perhaps not widely recognised, that occur in conjunction with a highly characteristic gingival lesion in Wegener's granulomatosis. To the best of our knowledge, this particular combination of clinical and histopathological features, when seen against the background of a systemic upset, has not been described before in association with any condition other than Wegener's granulomatosis.

\section{Case report}

A 36 year old woman presented to our unit complaining of a sore mouth and malaise of three weeks duration. Examination principally showed extremely swollen, erythematous gingivae, particularly in the upper and lower premolar regions, where there were natural teeth in good condition. The gums had a granular appearance and were flecked with yellow, resembling over-ripe strawberries (fig 1). The favoured clinical diagnosis was gingival Wegener's granulomatosis. An incisional biopsy of affected gum was performed.

The gingival biopsy specimen showed extensive pseudoepitheliomatous hyperplasia, with the stratified squamous epithelium extending into the stroma as deeply penetrating tongues and crypts. Within the oedematous connective tissues, there was an intense inflammatory infiltrate composed predominantly of neutrophils and eosinophils, with lesser numbers of plasma cells, lymphocytes, and macrophages. Focal clustering of neutrophils and eosinophils was noted, with microabscess formation. One of these microabscesses was seen rupturing into an epithelial crypt, and draining to the surface as a bead of pus. Several isolated multinucleate giant cells were present, but no necrosis, vasculitis, or granuloma formation were identified (figs 2-4). Special stains failed to reveal fungi. The pattern and degree of epithelial hyperplasia, the intensity of the inflammatory 


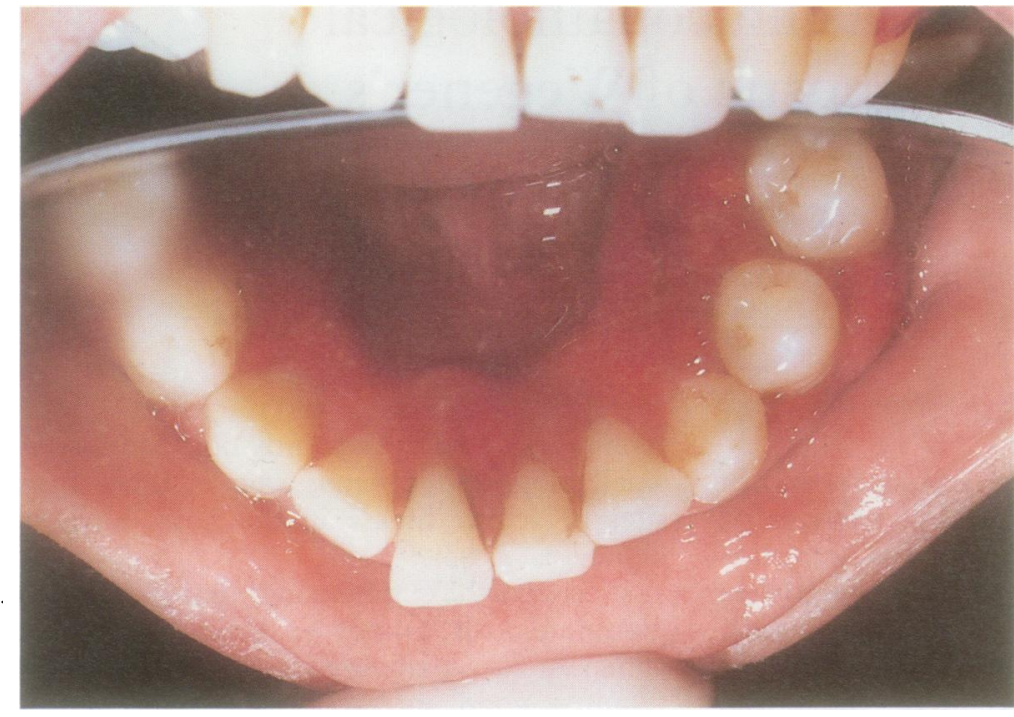

Figure 1 Reddened, swollen gingivae with yellow flecks affecting the lower incisor and premolar gingivae.

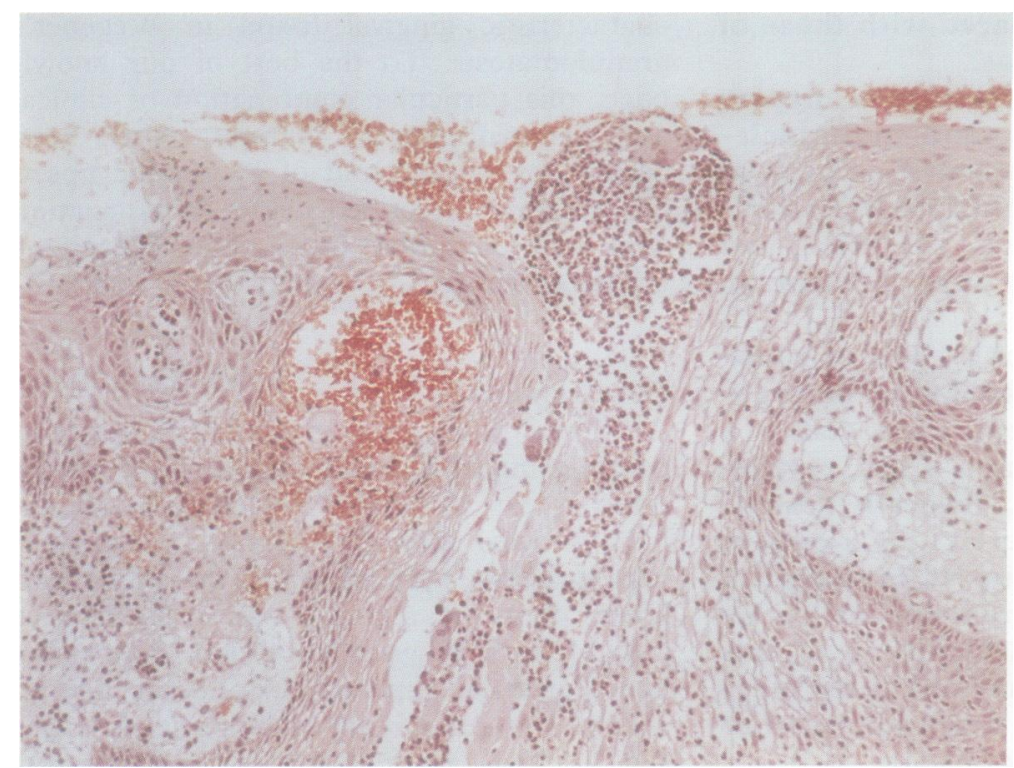

Figure 2 Detail from an area of pseudoepitheliomatous hyperplasia showing an intense inflammatory cell infiltrate with a bead of pus containing a multinucleate giant cell draining to the surface along an epithelial crypt.

Summary of previously reported histopathological features of Wegener's granulomatosis affecting gingiva

\begin{tabular}{|c|c|c|c|c|c|c|}
\hline Reference & $P E H$ & Microabscess & Giant cells & Vasculitis & Necrosis & $\begin{array}{l}\text { Granulomatous } \\
\text { infiltration }\end{array}$ \\
\hline 10 & + & + & + & - & - & + \\
\hline 12 & + & + & + & - & - & - \\
\hline 13 & + & + & + & - & - & + \\
\hline 15 & + & + & + & - & + & + \\
\hline 16 & + & + & + & - & + & + \\
\hline 17 & + & + & + & + & - & - \\
\hline 18 & + & + & + & - & - & - \\
\hline 19 & + & + & + & + & + & - \\
\hline 20 & + & + & + & - & - & - \\
\hline 21 & + & + & + & - & + & - \\
\hline $22(\mathrm{i})$ & + & + & NS & NS & NS & NS \\
\hline (ii) & + & NS & NS & NS & NS & NS \\
\hline 23 & + & + & + & + & - & - \\
\hline 24 & + & + & - & - & - & - \\
\hline
\end{tabular}

PEH pseudoepitheliomatous hyperplasia; + present; -absent; NS not specified. (In references 11 and 14 no specific details on the histopathological findings were reported). infiltrate and its tendency to cluster into microabscesses, together with the presence of several multinucleate giant cells were felt to be strongly suggestive of gingival Wegener's granulomatosis.

The patient was admitted to hospital to assess the extent of the disease. Examination of ear, nose, and throat, sinus and chest radiographs, and serological tests (including full blood picture, erythrocyte sedimentation rate (ESR), autoantibody screen, urinalysis and cANCA titres) were performed. Except for an ESR, which on two occasions was greater than $90 \mathrm{~mm}$ first hour, and a C-reactive protein concentration of $37.1 \mathrm{mg} / \mathrm{ml}$ (normal adult range under $6.0 \mathrm{mg} / \mathrm{ml}$ ), all other investigations were normal or negative. A granular area was identified on the left side of the nasal septum, from which the patient had complained of an episode of epistaxis. Although not biopsied, this area was felt to be "consistent with Wegener's granulomatosis" on clinical grounds.

Wegener's granulomatosis limited to the upper aerodigestive tract was diagnosed, and in an effort to avoid the side effects of immunosuppressive treatment, a course of co-trimoxazole ${ }^{8}$ was started. There was clinical improvement within three days and complete resolution within one week, the ESR and C-reactive protein concentrations returning to normal values in line with the clinical condition. ${ }^{9}$

\section{Discussion}

After correlation of all positive findings Wegener's granulomatosis was diagnosed in our case on the basis of three key features: (1) the multiple gingival lesions, which resembled over-ripe strawberries; (2) the patient's complaint of malaise (supported by increased ESR and C-reactive protein concentration); and (3) the histopathological appearances in the gingival biopsy specimen. The serological tests only helped to reinforce the clinical impression of a systemic inflammatory process and did not confirm the diagnosis of Wegener's granulomatosis. The cANCA titre, arguably the most useful investigation in cases of Wegener's granulomatosis, was non-contributory. Even the presence of the nasal lesion could not be considered diagnostic.

This particular combination of clinical and histological features was first described in a peculiar form of progressive hyperplastic gingivitis by Milner, ${ }^{10}$ when the association with Wegener's granulomatosis was made only at necropsy. Small numbers of similar cases have been reported since, most of which draw attention to the delay between initial presentation and diagnosis. ${ }^{11-24}$ These reports describe the histological features of pseudoepitheliomatous hyperplasia, polymorph microabscesses, and giant cells in the gingival biopsy (table), the appearances being generally regarded as those of non-specific active chronic inflammation. The classic criteria of vasculitis, granulomata, and necrosis are 


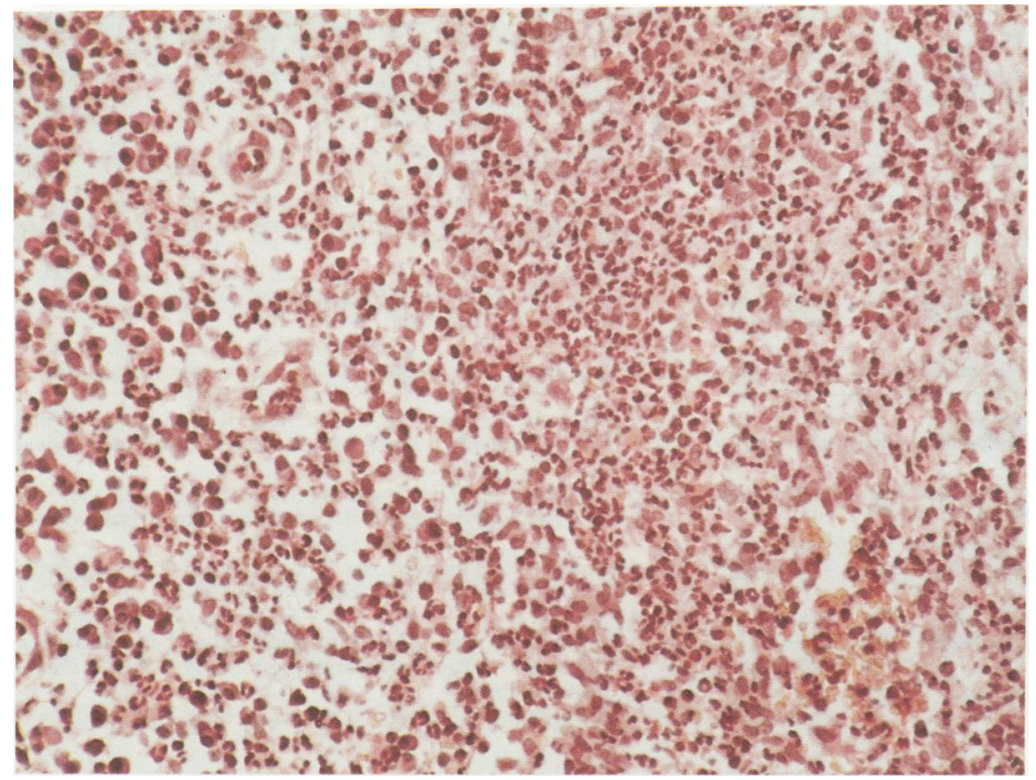

Figure 3 Clustering of neutrophils and eosinophils with microabscess formation (haematoxylin and eosin).

notably absent in most gingival biopsy specimens, although vascular changes consistent with vasculitis, 171923 an inflammatory process described as "granulomatous", 10131516 and small areas of necrosis 15161921 have been recorded. Often, only after disease progression with spread to "classical" sites or repeated biopsy is the diagnosis of Wegener's granulomatosis established.

Although generally regarded as non-specific, the pseudoepitheliomatous hyperplasia, the intense infiltrate of neutrophils and eosinophils with the formation of microabscesses, and the presence of multinucleate giant cells are seen in few other conditions affecting the gums. The degree of epithelial proliferation may suggest a squamous cell

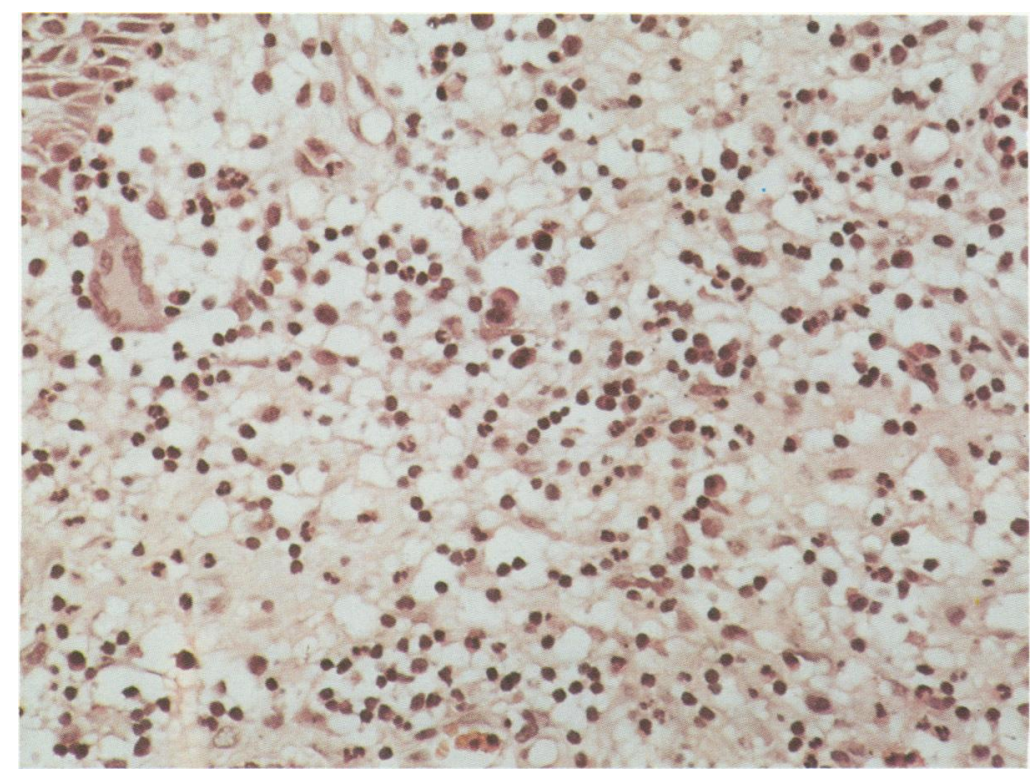

Figure 4 Inflammatory cell infiltrate of neutrophils, eosinophils, lymphocytes and plasma cells with a multinucleate giant cell in oedematous connective tissues adjacent to some stratified squamous epithelium (top left) (haematoxylin and eosin). carcinoma, but the overall pattern is more that of a reactive rather than a neoplastic process. Fungal infections-for example, histoplasmosis and paracoccidioidomycosis (South American blastomycosis) - can usually be excluded by simple histochemical stains, in that the fungae may be identified either within the tissues or the giant cells with periodic acid Schiff or methylamine silver stains. Conditions such as orofacial granulomatosis, Crohn's disease, and sarcoidosis, which may affect the gums and in which granulomata and multinucleate giant cells may occur, are quite distinct from Wegener's granulomatosis in that they do not show polymorph infiltration, microabscess formation, or the same degree of pseudoepitheliomatous hyperplasia. ${ }^{25}$ Eosinophilic granuloma (Langerhans' cell histiocytosis) may produce red, swollen, painful gingivae. Eosinophil microabscesses, necrosis, and multinucleate giant cells are seen in this condition, but the striking histological feature is the dense infiltrate of the Langerhans' cells-pseudoepitheliomatous hyperplasia is not a feature. ${ }^{26}$

Most authors acknowledge that the clinicopathological complex of "strawberry gums" plus the accompanying histopathological features of pseudoepitheliomatous hyperplasia, microabscesses, and multinucleate giant cells is "highly suggestive" of Wegener's granulomatosis. ${ }^{14-18202324}$ Indeed, we know of no association of the features of this complex with any other disease process. We feel that in an appropriate clinical setting they are so characteristic of gingival Wegener's granulomatosis as to be virtually diagnostic, particularly since the classic criteria of vasculitis, granulomata, and necrosis occur only rarely in gingival biopsy specimens.

The diagnosis of a condition as rare, as variable in both its clinical and histopathological features, and as serious as Wegener's granulomatosis will always require good clinicopathological correlation, requiring more specific histological features to be identified to establish the diagnosis the less clinical support there is for Wegener's granulomatosis. ${ }^{27}$ We believe that recognition of these lesions as part of the spectrum of Wegener's granulomatosis may speed diagnosis, particularly those cases where other diagnostic variables are likely to be absent.

1 Hunder GG, Lie TJ. The vasculitic syndromes. In: Stein $\mathrm{JH}$, Hutton J, Kohler PD, et al, eds. Internal medicine. Boston: Little, Brown and Co., 1990:696-9.

2 Nolle B, Specks U, Ludermann J, Rohrbach MS DeRemee RA, Gross WL. Anticytoplasmic autoantibodies: their immunodiagnostic value in W

3 Fienberg R. The protracted superficial phenomenon in pathergic (Wegener's) granulomatosis. Hum Pathol 989;12:458-67.

4 Batsakis JG, Luna MA. Midfacial necrotizing lesions. Semin Diagnost Pathol 1987;4:90-116.

5 Shah IA, Holstege A, Riede UN. Bioptic diagnosis of Wegner's granulomatosis in the absence of vasculitis and granulomas. Path Res Pract 1984;178:407-12.

6 Del Buono EA, Flint A. Diagnostic usefulness of nasa biopsy in Wegener's granulomatosis. Hum Pathol 1991;22:107-10.

7 Colby TV, Tazelaar HD, Specks U, DeRemee RA. Nasal 
biopsy in Wegener's granulomatosis. Hum Pathol 1991;22:101-4.

8 DeRemee RA, McDonald TJ, Weiland LH. Wegener's granulomatosis: observations on treatment with antimicrobial agents. Mayo Clin Proc 1985;60:27-32.

9 Napier SS, Allen JA, Irwin CR, McCluskey DR. Strawberry gums: a case of Wegener's granulomatosis. Br Dent $\mathcal{f}$ (in press).

10 Milner PF. Nasal granuloma and periarteritis nodosa. $\mathrm{Br}$ Med $\mathcal{f}$ 1955;2:1597-9.

11 Morgan AD, O'Neil $\mathrm{R}$. The oral complications of polyarteritis and giant cell granulomatosis (Wegener's granulomatosis). Oral Surg 1956;9:845-857.

12 Cawson RA. Gingival changes in Wegener's granulomatosis. Br Dent f 1965;118:30-2.

13 Kakehashi S, Hammer JE, Baer PN, McIntire JA. Wegener's granulomatosis. Report of a case involving the gingiva. Oral Surg 1965;19:120-7.

14 Brooke RI. Wegener's granulomatosis involving the gingivae. Br Dent F 1969;127:34-6.

15 Scott J, Finch LD. Wegener's granulomatosis presenting as gingivitis. Oral Surg 1972;34:920-33.

16 Edwards MB, Buckerfield JP. Wegener's granulomatosis: a case with primary mucocutaneous lesions. Oral Surg 1978;46:53-63.

17 Cohen PS, Meitzer JA. Strawberry gums: a sign of Wegener's granulomatosis. $\mathcal{F} A M A$ 1981;246:2610-11

18 Israelson H, Binnie WH, Hurt WC. The hyperplastic gin-
52:81-7.

19 Raustia AM, Autio-Harmainen HI, Knuuttila MLE, Raustia JM. Ultrastructural findings and clinical followup of "strawberry gums" in Wegener's granulomatosis. f Oral Pathol 1985;14:581-7.

20 Handlers JP, Waterman J, Abrams AM, Melrose RJ. Oral features of Wegener's granulomatosis. Arch Otolaryngol 1985;111:267-70

21 Horan RF, Kerdel FA, Moschella SL, Haynes HA. Recent onset of gingival enlargement. Arch Dermatol 1986;122:1436-9.

22 Cohen RE, Cardoza TT, Drinnan AJ, Aguirre A, Neiders ME. Gingival manifestations of Wegener's granuloME. Gingival manifestations of W

23 Allen CM, Camisa C, Salewski C, Weiland JE. Wegener's granulomatosis: report of three cases with oral lesions. ₹ Oral Maxillofac Surg 1991;49:294-8.

24 Parsons E, Seymour RA, Macleod RI, Nand N, Ward MK. Wegener's granulomatosis: a distinct gingival lesion. 7 Clin Periodontol 1992;19:64-6.

25 Wiesenfield D, Ferguson MM, Mitchell DN, et al. Oro-facial granulomatosis-a clinical and pathological analysis. $O f$ Med 1985;54:101-13.

26 Hatman $\mathrm{KS}$. Histiocytosis X. a review of 114 cases with oral involvement. Oral Surg 1980;49:38-54.

27 Devaney KO, Travis WD, Hoffman G, Leavitt R Lebovics R, Fauci AS. Interpretation of head and neck biopsies in Wegener's granulomatosis. Am $\mathcal{F}$ Surg Pathol 1990;14:555-64. 